

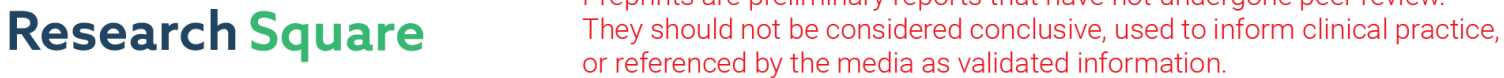

\section{An Environmental Information System for the Exploration of Energy Systems}

\section{Karsten Rink ( $\nabla$ karsten.rink@ufz.de )}

Helmholtz-Zentrum fur Umweltforschung GmbH - UFZ Zentralbibliothek https://orcid.org/0000-00019826-8221

\section{Özgür Ozan Şen}

Helmholtz-Centre for Environmental Research - UFZ: Helmholtz-Zentrum fur Umweltforschung UFZ

\section{Malte Schwanebeck}

University of Kiel: Christian-Albrechts-Universitat zu Kiel

\section{Tim Hartmann}

University of Kiel: Christian-Albrechts-Universitat zu Kiel

\section{Firdovsi Gasanzade}

University of Kiel: Christian-Albrechts-Universitat zu Kiel

Johannes Nordbeck

University of Kiel: Christian-Albrechts-Universitat zu Kiel

\section{Sebastian Bauer}

University of Kiel: Christian-Albrechts-Universitat zu Kiel

\section{Olaf Kolditz}

Helmholtz-Centre for Environmental Research - UFZ: Helmholtz-Zentrum fur Umweltforschung UFZ

\section{Research Article}

Keywords: Scientific visualisation, Energy system infrastructure, Energy storage, Heat demand density, CAES, ATES, Knowledge transfer

Posted Date: November 30th, 2021

DOI: https://doi.org/10.21203/rs.3.rs-1081713/v1

License: (9) This work is licensed under a Creative Commons Attribution 4.0 International License. Read Full License

Version of Record: A version of this preprint was published at Geothermal Energy on March 19th, 2022. See the published version at https://doi.org/10.1186/s40517-022-00215-5. 


\title{
RESEARCH
}

\section{An Environmental Information System for the Exploration of Energy Systems}

\author{
Karsten Rink ${ }^{1 *}$, Özgür Ozan Şen ${ }^{1}$, Malte Schwanebeck ${ }^{2}$, Tim Hartmann ${ }^{3}$, Firdovsi Gasanzade ${ }^{4}$, Johannes \\ Nordbeck $^{4}$, Sebastian Bauer ${ }^{4}$ and Olaf Kolditz ${ }^{1,5}$
}

\author{
* Correspondence: \\ karsten.rink@ufz.de \\ 1 Department of Environmental \\ Informatics, Helmholtz-Centre for \\ Environmental Research - UFZ, \\ Leipzig, Germany \\ Full list of author information is \\ available at the end of the article
}

\begin{abstract}
The transition to renewable energy sources requires extensive changes to the energy system infrastructure ranging from individual households to the national scale. During this transition, stakeholders must be able to make informed decisions, researchers need to investigate possible options and analyse scenarios and the public should be informed about developments and options for future infrastructure. The data and parameters required for this are manifold and it is often difficult to create an overview of the current situation for a region of interest. We propose an environmental information system for the visualisation and exploration of large collections of heterogeneous data in the scope of energy system infrastructure and subsurface geological energy storage technologies. Based on the study area of Schleswig-Holstein, a federal state in Germany, we have set up a virtual geographic environment integrating GIS data, topographical models, subsurface information, and simulation results. The resulting application allows users to explore data collection within a unified context in 3D space, interact with datasets, and watch animation of selected simulation scenarios to gain a better understanding of the complex interactions of processes and datasets. Based on the cross-platform game engine Unity, our framework can be used on regular PCs, head-mounted displays, and virtual reality environments and can support domain scientists during assessment and exploration of the data, encourages discussions and is an effective means for outreach activities and presentations for stakeholders or the interested public.
\end{abstract}

Keywords: Scientific visualisation; Energy system infrastructure; Energy storage; Heat demand density; CAES; ATES; Knowledge transfer

\section{Motivation}

To lower $\mathrm{CO}_{2}$-emissions and limit the consequences of climate change, adjusting energy production to use renewable sources of energy is a crucial step (Buonocore et al, 2016; Masson-Delmotte et al, 2018; Spillias et al, 2020). To prevent global warming, the transition to renewable energy sources is being widely examined in recent years. However, these renewable energy sources often have a strongly fluctuating weather-dependent nature and may be seasonally limited, which impairs the stability and security of the energy system (Schiebahn et al, 2015). For example, long term heat storage is necessary to integrate renewable heat resources like solar-thermal energy, geothermal energy, or waste heat into urban district heating systems to balance the seasonal change in demand and production and coupling the sectors of heat and electricity (Brown et al, 2018). One contribution to solve these issues is the use of large scale storage technologies (Adamek et al, 2012; Weitemeyer 
et al, 2015). Subsurface geological storage can provide the large storage capacities required to support sub-daily to multi-year storage cycles (Kabuth et al, 2017), thus buffering loads and providing security and stability. The main geological storage technologies include the geological storage of synthetic hydrogen (Li et al, 2018; Mouli-Castillo et al, 2019; Pfeiffer et al, 2021) or methane, compressed air energy storage (Wang and Bauer, 2016) as well as thermal energy storage by using open or closed loop systems.

In order to assess the potential as well as technical options for energy storage in the subsurface, information on the energy system, including spatially and temporally resolved energy demand and production, as well as information on the subsurface such as geological structures and material parameters related to the storage processes are required (Bauer et al, 2013, 2017). To address these requirements, a very large and diverse data collection is needed, containing various time and space scales, dimensionality as well as inherent complexity and inter-connectivity. Some of the required data has been collected for the model region of Schleswig-Holstein, a federal state in the North of Germany, and used for analysing subsurface energy storage options. This data collection has been used to create an overview of spatial data on energy infrastructure, the current status of renewable energy sources, and energy demand of Schleswig-Holstein, in combination with potential options for the storage of gas or heat in the subsurface to compensate for producer fluctuations and seasonal variability (Attard et al, 2020; Bayer et al, 2019; Kabuth et al, 2017; Tissen et al, 2019). While part of the relevant datasets are georeferenced vector and raster data that can be explored in a geographic information system (GIS), a fair number use a variety of non-GIS-conform file formats (3d models, numerical simulation results, etc.) which makes it difficult to collate all relevant data sets within a single geographic context. In addition, a comprehensive overview requires a $3 \mathrm{D}$ visualisation of the data collection for consideration of geological information or underground energy storage and representation of transient processes over time. Therefore, we propose the use of an environmental information system (EIS) that offers an interactive framework and allows data exploration within a 3D environment, illustrates the interaction of multiple datasets, supports linking of data sets to each other and supports the animation of observation data or simulation results to display changes in the environment over time.

A short overview of environmental information systems will be given in the following section. We will then introduce the region of interest and present details on datasets and preprocessing steps for this particular study. Finally, the proposed framework for an environmental information system will be described along with decisions for the visualisation of the available data. We will finish with conclusions and possible extensions of the proposed framework.

\section{Related Work}

There is no clear-cut definition on what comprises an environmental information system. Haklay (1999) distinguishes two principal types of information systems: systems for storing and retrieving information and system for the analysis and visualisation of data. In environmental sciences, the first type deals in metadata and data management (Günther, 2013) and will be largely ignored in the following (in 
particular as data sets within this study are file-based and often too large for to interactively import from databases). Instead, we are focussing on the second type of systems which also includes software such as geographical information systems. Similar to GIS, we are aiming to overcome the challenges of integration, visualisation and exploration within environmental data collections. With the increased amount of observation of natural phenomena in recent years due to progress in technology, production, and accuracy of equipment, this has become an important research topic (Buck et al, 2021; Helbig et al, 2017). Examples for heterogeneous data collections in 3D space have been previously presented for applications in hydrology (Porter et al, 2021; Rink et al, 2012), emergency management (Wang et al, 2017), meteorology (Helbig et al, 2014) or oceanography (González et al, 2021). For the state of Schleswig-Holstein, Nolde et al (2016b) have published a 3D WebGIS for the spatial planning of underground energy storage. Some examples support exploration in virtual reality to enhance immersion and provide additional options for data exploration (Chen et al, 2015; Lin et al, 2013; Rink et al, 2021). In that sense, an EIS is a collection of data sets and information that have some relevance for a given study regarding monitoring, modelling, or exploration of the environment. The main challenge is then an adequate visualisation strategy for a wide range of raw environment data representing different contexts and acquired from different sources. This includes the representation of data in 3D space (Vessey, 2006) as well as dealing with issues such as perspective, occlusion (Elmqvist and Tsigas, 2008), interaction, or highlighting interesting datasets or features within a scene.

In the following we present a prototype for such an environmental information system embedded within a virtual geographic environment for giving an overview of regional energy systems and storage options for the federal state of SchleswigHolstein in Germany.

\section{Data Preprocessing}

The potential for generation of renewable energy and subsequent storage in the subsurface has been thoroughly investigated for the state of Schleswig-Holstein in Germany because of it's unique geographical and geological properties (Fricke, 2018; Nolde et al, 2016a). The main focus of the research is to explore and visualize the transition to renewable energy sources and impacts of the use of the geological subsurface for energy storage.

To support communication between researchers from different domains and facilitate outreach activities to regional stakeholders concerned with energy systems as well as the interested public, a prototype for a a comprehensive graphical Environmental Information System (EIS) has been developed, based on a Virtual Geographic Environment (VGE). This EIS allows to explore complex datasets, investigate the interrelation between datasets and develop a better understanding and insight on the available options for a transition to renewable energy for regional authorities, businesses and private households.

As a basis for our application we use an extensive collection of heterogeneous datasets with large variances in structure, resolution and extent. Categories include raster data, vector data, point data and time series data, but also volume datasets used for modelling and simulation of the subsurface. Spatial datasets have been 
transformed into the same geographic coordinate system, in this case UTM zone $32 \mathrm{~N}$ (EPSG:25832), either via geographic projection in QGIS (QGIS Development Team, 2009) or via geometric transformation using the OpenGeoSys Data Explorer (Rink et al, 2014).

\section{Topographic Frame of Reference}

To provide context for all subsequent datasets, we first created a georeferenced topographic frame of reference covering the German state of Schleswig-Holstein with a size of $15763 \mathrm{~km}^{2}$ as well as circa $25000 \mathrm{~km}^{2}$ of marine area in the German part of the North Sea and, to a much smaller extent, the Baltic Sea (see Fig. 1a). Geometrical data for the region of interest has been imported into the OpenGeoSys Data Explorer to create a triangulated surface (Rink et al, 2013) consisting of 980000 triangles with an average edge length of $250 \mathrm{~m}$. Node elevation is based on a digital elevation model with a resolution of $25 \mathrm{~m}$ (Landesamt für Vermessung und Geoinformation Schleswig-Holstein, 2019b). The state has a flat topography with a maximum difference in elevation of $160 \mathrm{~m}$, which is difficult to notice given the total area of Schleswig-Holstein at over $15000 \mathrm{~km}^{2}$. To increase the effect of a 3D surface, it is optionally possible to superelevate the surface by applying a scaling factor to the $z$-components of mesh nodes. Displaying the correct surface elevation is required in the context of subsurface data added to the scene, such as geological layers and simulation results. For a more realistic impression of the scene as well as to allow for better orientation for users, we have added two textures that can be applied to the surface topography: a high resolution satellite image of Schleswig-Holstein from Google Earth (Google, GeoBasis-DE/BKG (C2009) as well a monochrome map from OpenStreetMap (C)OpenStreetMap-contributors). Both maps display a map section that covers the whole of the state at a scale of $1: 100000$ and have a raster size of $8192 \times 8192$ pixels. In addition, the municipality area of the four major cities, Kiel, Flensburg, Neumünster and Lübeck (GeoBasis-DE/BKG, C2021), can be highlighted on the topographic surface (see Fig. 1a) as landmarks to provide context.

\section{Subsurface Information and Gas Storage}

Subsurface information for this study area relates to the North German Basin. Over the last decades, the geological structure for parts of the basin has been thoroughly investigated and well documented (Arfai et al, 2014; Baldschuhn et al, 2001; Hese, 2012; Jähne-Klingberg et al, 2014; Wolf et al, 2014). Gasanzade et al (2021) combined all available literature data for the subsurface potential assessment into a 3D structural geological model. In this study, only the three main storage formations: the Dogger (Middle Jurassic), the Rhaetian (Upper Keuper) and the Middle Buntsandstein are used for visualisation. The storage formation depth horizon maps are derived from Petrel E\&P platform (Schlumberger Ltd, 2018) as triangulated surfaces consisting from 200000 to 950000 number of triangles and are displayed using the associated colours used in geological maps. Fig. 2a shows the main regional tectonic structures from the Entenschnabel graben systems (Northwestmost) to the Eastholstein block. 
Georeferenced datasets illustrating the existing renewable energy production infrastructure for electric power in Schleswig-Holstein (Fig. 1) are given in point and vector data format. In particular, point data sets representing wind turbines, and biogas plants plus the locations of transformation stations have been mapped onto the triangulated topographic surface of the federal state. In addition, polygons specifying the spatial extent of solar parks as well as onshore and offshore wind parks have been tesselated and both these polygons as well as polylines marking power lines have been subsequently also mapped such that they are positioned at the same elevation as the topographic surface (Rink et al, 2014).

In addition to static raster and vector data representing topography and energy system infrastructure, this study also includes 3D dynamic simulation results of compressed air energy storage (CAES) and aquifer thermal energy storage (ATES) facilities are visualised. This enables integrated analysis of geological subsurface dimension for energy storage applications.

Simulation results of CAES consist of two technological setups: The first setup has a three-stage compression and a two-stage expansion with heat recuperator in the power plant as implemented in McIntosh (USA). The second concept simulates an adiabatic power plant with three-stage compression and expansion parts. Both setups are designed for a future energy system with a high penetration of renewables (i.e. $76 \%-100 \%$ ), where 9 vertical storage wells at $1 \mathrm{~km}$ depth deliver the required air mass flow rate to generate $115 \mathrm{MWh}$ electrical energy at the power plant. CAES simulations are carried out via a coupled interface simulator developed by Pfeiffer et al (2021) and subsequent simulation results are converted into VTK data structures (Schroeder et al, 2006) using a mesh converter proposed by Wang and Bauer (2016). The resulting 3D meshes consists of 210160 hexahedral elements each and include static depth values as well as total pressure and air saturation for annual storage operations stored in 13 timesteps.

The compressed air energy storage facility stores pressurised air in a subsurface porous formation using off-peak power, which is released during peak demand using a turbine for power generation. In this study, we are aiming to integrate all these units to better surface and subsurface space analysis. All nine vertical wells on top of the anticline storage structure are integrated with a virtual power plant model at the surface ${ }^{[1]}$, which supports appropriate surface and subsurface facility design (see Fig. 2b). In case of the diabatic CAES setup, the required heat during power generation should be delivered from a reference power plant. This need not necessarily be the designated peak load power plant but could conceptually be achieved via one or more of the existing biogas plants in the area.

\section{Aquifer Thermal Energy Storage}

The second dataset shows the temperature distribution during system operation of a high temperature aquifer thermal energy storage (HT-ATES) simulation model (see Fig. 3. The model is part of a larger study, which analyses HT-ATES systems and their role in future urban heat supply systems. Such systems can provide the capacity for heat energy to bridge short-term intervals and seasonal fluctuations

\footnotetext{
${ }^{[1]}$ https://www.thingiverse.com/thing: 2339011
} 
using renewable energy and thus increase the overall share of renewables in the heating sector. Such systems are planned for a number of cities in Germany, such as Berlin, Hamburg, Leipzig (Fatima et al, 2021; Hassanzadegan et al, 2016; Kastner et al, 2017; Krawczyk et al, 2019; Müller, 2021; Scheck-Wenderoth et al, 2017). The geological subsurface of this particular models is based on the subsurface of one of the districts of Kiel, the capital city of Schleswig-Holstein. It consists of alternating layers of sand and clay, which is typical for northern German Pleistocene formations. The HT-ATES installation consists of four well doublets of a warm and cold well each, which are installed into a depth of $100 \mathrm{~m}$ with a screen length of $20 \mathrm{~m}$ across the whole aquifer. The cold and warm wells of each doublet are $300 \mathrm{~m}$ apart, while the doublets have a spacing of $100 \mathrm{~m}$. The aquifer is bounded on top and bottom by glacial till, i.e. clay. During storage charging, ambient temperature water is extracted from the cold well, pumped through a heat exchanger and injected into the warm well. During storage discharge hot water is extracted from the warm well and brought to the district heating network flow temperature level using a heat pump. The four well doublet setup reaches storage rates of up to $12 \mathrm{MW}$ with a storage capacity of $25 G W h$. The HT-ATES FEM model consists of 575000 hexahedron, pyramid, and prism elements in a $1600 \times 1500 \times 205 \mathrm{~m}$ model area. The governing differential equations of liquid flow and heat transport are solved using the simulation software OpenGeoSys, a process- and object-oriented open source software (Kolditz and Bauer, 2004; Kolditz et al, 2012). Simulation results of this model consist of 3650 time steps and include pressure, temperature, and velocity for all elements.

To give context to heat storage systems using the aforementioned setups, the visualisation study also contains data illustrating the annual building heat demand density. Refurbishment of the existing building stock is necessary to lower heat demand and the construction of renewable heating systems that use heat storage technologies is necessary to lower emissions from energy supply covering the remaining heat demand of the building stock as the energy demand for heating and hot water provision in buildings has a big share of $\mathrm{CO}_{2}$ emissions. To achieve this goal, laws for mandatory "heat planning" on municipality level are now being introduced in Germany. Both, location and density of heat demand is an important aspect for heat planning (Nielsen, 2014). High detailed spatial data on measured heat demand is rare and often not accessible because it is protected by privacy

laws, but can be modelled and mapped using available geodata such as 3D building models, census data, and building typologies (DeJaeger et al, 2018; Nouvel et al, 2017; Schwanebeck et al, 2021; Wate and Coors, 2015). A "heat atlas" can support heat planning on different spatial levels by integrating geodata on heat demand with geodata on heat production and heat storage potential (Möller et al, 2019). A heat density distribution map in $M W h / \mathrm{km}^{2}$ for Schleswig-Holstein, originally published by Schwanebeck et al (2021), has been integrated into this study as shown in Fig. 4c.

\section{Visualisation of Urban Infrastructures}

A special focus within this visualisation study is the city of Kiel. Being the capital city of the state of Schleswig-Holstein with a population of nearly 250.000 people, 
the city is of particular interest both from a geographic point of view in terms of energy demand as well as from a visualisation point of view regarding the representation of urban areas. Therefore, the workflow previously presented for the state of Schleswig-Holstein has alsobeen applied for a region of interest representing this city: A topographic surface of the area covered by the city has been created, consisting of 30000 triangles with an average edge length of $100 \mathrm{~m}$. A high-resolution airial image with a resolution of $2439 \times 4069$ pixels acquired from Google Earth (Google, GeoBasis-DE/BKG (C)2009) can be applied for context, as shown in Fig. 4a. In addition, a raster illustrating heat demand density for the city with a pixel size of one hectare (Fig. 4b) can be applied as a texture to this surface.

As a prototypical example, LoD1 data (Landesamt für Vermessung und Geoinformation Schleswig-Holstein, 2019a) for all buildings in one district of the city of Kiel has been provided by the federal-state's surveying agency. In this context, "LoD1" ("level of detail 1") refers to datasets where both the building footprint and the average roof height of each building are specified. For that one district, the dataset consisted of over 30000 polylines that have been mapped onto the topographic surface and subsequently used to generate almost 3500 models of individual buildings (see Fig. 5).

The next section will introduce our proposed framework and give details on the integrated visualisation of the datasets introduced above.

\section{Visualisation}

A Unity (Unity Technologies, 2020) based framework previously introduced for the setup of virtual geographic environments for hydrological (Rink et al, 2020) and hydro-meteorological (Rink et al, 2021) studies has been adapted to create an EIS for this study on energy systems. Existing functionality in terms of data import, data representation, presentation-specific features and environmental interaction have been adjusted and extended to provide a suitable framework for the datasets and required interaction to create an environmental information system for this particular study.

After preprocessing all dataset as described in the previous section, the topographic surfaces and datasets are separately converted into glTF (Bhatia et al, 2017) intermediary 3D model files and subsequently imported into the Unity framework. The prerequisite of datasets using the same geographic projection ensures the correct positioning of all graphical object with respect to each other and prevents the need of further manual adjustments in the 3D scene.

The aforementioned reference frame is defining the geographical extent of the scene. In accordance with topographic maps, surfaces representing land mass are shaded in solid green color while marine regions are illustrated in blue. For the surface of Schleswig-Holstein in particular, one of two geographic maps (Google satellite or OpenStreetMap monochrome imagery) are applied at any time to provide extra context for the geolocations of additional data sets and can be switched during runtime according to the current state of the $3 \mathrm{D}$ scene.

Specific sites of various types of energy infrastructure have been imported into Unity as point topology meshes where each point includes a facility's location as well as additional cell properties (an examples of this are the height and maximum 
power output for individual wind turbines). A consistent and intuitive colour scheme was applied to make structures easily distinguishable. Specifically, solar parks are displayed in yellow, biogas plants in green, wind parks and turbines in blue, and power lines and transformation stations in red. A first approach displaying the various data sets as point clouds was rejected, as points have no discernable features and the multitude of coloured points scattered across the surface looked rather abstract. Instead, we included open-source 3D models of solar panels ${ }^{[2]}$, wind turbines $^{[3]}$, transformation stations ${ }^{[4]}$, and biogas plants ${ }^{[5]}$ to represent each facility at its vertex location and applying the previously mentioned colour scheme. This makes infrastructure easily distinguishable by colour when viewed from a large distance (similar to point representations), while the use of 3D models adds an immersive and intuitively recognisable component when the user is at a close distance within the 3D space. From a technical perspective, we applied a model composer script to create the respective model for every vertex in the point cloud with the correct transformation properties (i.e. scale, translation and rotation). This approach additionally allows a parameterisation of each point, for instance by dynamically adjusting the height of each wind turbine model scaling with the height of the actual turbine it is representing. The spatial extent of wind- and solar parks are displayed as coloured surfaces (using the same colour scheme as the point data) and power lines are displayed using a geometry shader, ensureing that lines are visualised at a constant thickness, independent of camera distance to the object. A colour gradient ranging from red to orange represents the the voltage of individual power lines. In the same manner, the power output of wind turbines is represented by an interpolated colour gradient ranging from ultramarine for high power output to turquoise for low output (see Fig. 1b).

The integration of subsurface data into this study - especially of transient simulation results for the storage of energy - and their relation to energy infrastructure are one of the focus points of this study. These datasets require a 3D context and framework with interaction and exploration methods beyond the scope of a traditional GIS. An illustration of the storage formation distribution below the region of interest is shown in Fig. 2a. The modelled CAES facility is located within the Rhaetian sandstone formation in the easternmost part of study area at a depth of $1 \mathrm{~km}$. We included the saturation and pressure distribution of simulation results for one year for both adiabatic and diabatic surface power plant setups. Animations of the simulation results can be controlled via media-player-like controls as part of an interactive user interface and allow playing/pausing the simulation as well the selection of specific time steps. Displayed are interpolated values for the parameters of interest (e.g. pressure) within the geological storage layer by using a colour transfer function ranging from yellow (low pressure) to red (high pressure). In addition, iso contour lines are mapped onto the simulation result for the illustration of pressure distribution equidistant steps of 5 bars (see Fig. 2b).

For the visualisation of the four well doublets of the Aquifer Thermal Energy Storage simulation result below the modelled city district of Kiel, an animation

\footnotetext{
${ }^{[2]}$ https : //www.turbosquid.com/3d-models/solar-panel-3d-model-1171717

${ }^{[3]}$ https : //www . turbosquid.com/3d-models/free-3ds-model-environmentally-friendly/964716

${ }^{[4]}$ https://www . turbosquid.com/3d-models/substation-line-3ds-free/1114062

${ }^{[5]}$ https: //www. thingiverse.com/thing: 3398634
} 
of groundwater temperature values can be displayed within the 3D scene. In this case, we show iso-surfaces for specified temperature values. Given a value range of $\left[12.8^{\circ} \mathrm{C}, 75.1^{\circ} \mathrm{C}\right]$, seven iso temperatures are shown for $14,18,23,33,43,53$, and $63^{\circ} \mathrm{C}$, resulting in roughly equidistant contour surfaces. Specific values can easily be adjusted in preprocessing, but not currently within the Unity framework itself. For a better insight into the temperature distributes inside the high temperature bubbles for each borehole, iso temperature surfaces have been additionally clipped at the injection depth (see Fig. 3]. With these filters being automatically applied to all 3650 time steps, the data set is imported into the environmental information system with the same controls being available as for the gas storage simulation results. A standard rainbow colour table is applied to the values, ranging from dark blue for low temperatures up to red for high temperatures. Since iso values are displayed in 3D for this dataset, a separate colour legend is displayed as a $2 \mathrm{D}$ overlay within the scene for value attribution.

While the ATES simulation has not been modelled specifically to store energy for the city of Kiel, it is a plausible scenario for the selected district given the geological subsurface structures, district heating flow and return temperatures. We have included higher resolution data for elevation, heat demand, and airial imagery for a subregion encompassing the city and have also added the LoD1-based models of buildings for one of the city districts of Kiel. This results in a holistic view of the city structures in combination with subsurface energy storage.

The information on heat demand, both for the city of Kiel and the state of Schleswig-Holstein, is applied as a texture to the topographic surface, using a colour scale where white and yellow signify a low demand and red a high demand.

Given a georeferenced visual representation of all datasets included in the study, it is now possible to use the general features of our visualisation framework to create an interactive 3D scene for the exploration of the available data. The framework allows the import of 2D and 3D polygonal data, point clouds, line-based vector data and time series data which is represented in either glTF (Bhatia et al, 2017) or fbx (Autodesk Inc, 2020) static and animated model formats. If necessary, affine transformation properties can be adjusted easily based on the semantic representation of related data. Translation, rotation and scale can be adjusted during the design stage of the virtual reality scene as well as during runtime, resulting in animated transformations. Properties such as colour, textures, or transparency can also be configured to conform to domain scientists' visual experience, either during the setup stage or runtime. Point data clouds and line-based vector data can be represented meaningfully using fragments consisting of simple arbitrary shapes by employing custom geometry shader batches on the GPU. This results in the overall loading time being shorter and the application data requiring less storage space since the processing of the data is calculated on the GPU during runtime. For example, in this study, electric power lines are visualized with the help of custom GPU shaders and predefined 3D model geometries are drawn at the vertices of of point and line based datasets to depict solar, wind and biogas operated energy facilities within the study, as previously described. 
The framework allows to create an interactive scene, adopting all datasets and simulation results to construct a scenario within which domain scientists are able to explore and analyse environmental impacts and effects. In particular, it is possible to predefine viewpoints for areas of interest and to associate dataset visibilities with each individual viewpoint. That means triggering a viewpoint will cause a subset of the data to become visible (either fully opaque or transparent) while another subset will vanish. Camera paths can be defined as well, such that a "virtual tour" of the scene can be planned in advance. Independent of predefined settings, datasets can be shown/hidden via a user interface during runtime and additional supplemental data (such as images, documents, websites, videos, etc.) can be linked to datasets. Clicking on a particular dataset will then open a 2D overlay window to display additional information. As mentioned, animations for time-dependent data can be controlled via the user interface as well and colour legends can be stored for any dataset and displayed when required for interpretation.

The resulting application can be built for a wide range of visualisation hardware. While running perfectly fine as a conventional 3D application on a regular computer, the intended use is within a virtual reality environment. Therefore, stereoscopic virtual reality applications can also be created for head-mounted displays such as Oculus Quest or HTC Vive or even cave-like environments and visualisation centres. Likewise, input devices range from regular keyboard and mouse setups to specialised input devices such as Flystick or Vive Controllers. In addition, Unity also provides a utility to record movies of interactive sessions for presentation on any machine or via the web.

The resulting EIS supports domain scientists during assessment and exploration of the data collection, encourages discussions between scientists and is an effective means for outreach activities and presentations for stakeholders or the interested public.

\section{Conclusions and Future Work}

We have presented a prototype for an environmental information system for the exploration of energy systems, including renewable energy generation, energy demand, and storage, in the state of Schleswig-Holstein, Germany. The framework has been implemented using Unity and includes implementations for the import, transformation, and visualisation of environmental data. Users can interactively explore the existing infrastructure for the generation of energy from wind, biogas or solar power, data on energy demand, and the process of storing and extracting that energy in subsurface structures, using both CAES and ATES approaches. The framework can be extended by adding additional datasets and could also be used for creating a similar case study for a different region of interest, as all implementations regarding the modification and visualisation of the data are generic and can thus be applied for future case studies as well.

A straightforward extension of the existing prototype would include the representation of additional datasets, in particular linking actual time series data to the infrastructure. The functionality to pick any object (e.g. a wind turbine or biogas plant) and display a diagram illustration energy generation over time is already included although the data itself is missing at this point. In a similar way, additional 
information can be linked to any other object in scene. Besides providing a tool to further discussions and support outreach activities, a potential application for an EIS such as this could include testing different scenarios. Actual or potential numbers for generated energy could be used as input for the simulation software to create numbers regarding capacity of the gas storage and the temperature changes within the groundwater, for CAES and ATES, respectively. Available energy from storage can then be linked to heat demand and show the ratio of renewable versus fossil energy sources or the requirements of additionally required infrastructure to close that gap. As such, we believe an extension of the presented prototype as great potential for communicating requirements and research results to both stakeholders and an interested public to facilitate discussion and necessary changes to the energy system infrastructure within the model region.



\section{Funding}

Funding for the project was provided by the German Federal Ministry of Economic Affairs and Energy under Grant No. 03ET6122B ("ANGUS II: Impacts of the use of the geological subsurface for thermal, electrical or material energy storage in the context of the transition to renewable energy sources - Integration of subsurface storage technologies into the energy system transformation using the example of Schleswig-Holstein as a model area") and is gratefully acknowledged. This work is also part of the EASyQuart project "Energy-efficient design and planning of decentralised supply networks for heating and cooling of urban areas using the shallow subsurface" funded by the Federal Ministry for Economic Affairs and Energy (Grant No 03EGB0016C) which is gratefully acknowledged.

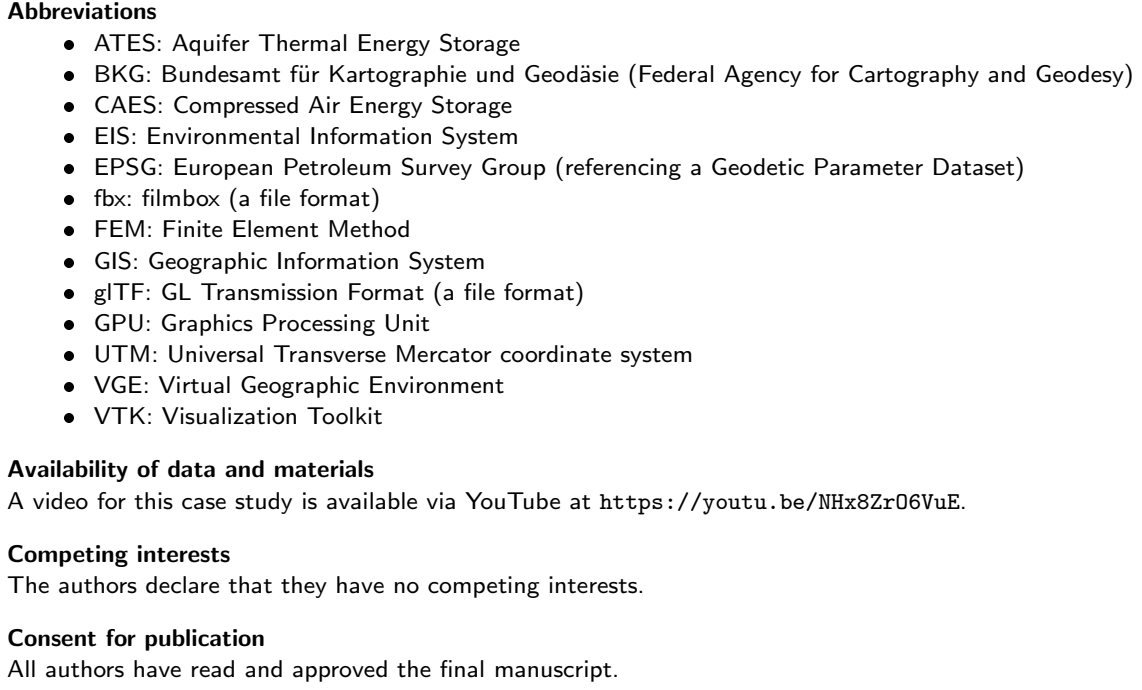


References

Adamek F, Aundrup T, Crotogino F, Glaunsinger W, et al (2012) Energiespeicher für die Energiewende: Speicherungsbedarf und Auswirkungen auf das Übertragungsnetz für Szenarien bis 2050. Tech. rep., VDE Association for Electrical, Electronic \& Information Technologies, Frankfurt am Main, Germany

Arfai J, Jähne F, Lutz R, Franke D, Gaedicke C, Kley J (2014) Late Palaeozoic to Early Cenozoic geological evolution of the northwestern German North Sea (Entenschnabel): New results and insights. Geol Mijnbouw 93:147-174, DOI:10.1017/njg.2014.22

Attard G, Bayer P, Rossier Y, Blum P, Eisenlohr L (2020) A novel concept for managing thermal interference between geothermal systems in cities. Renew Energ 145:914-924, DOI:10.1016/j.renene.2019.06.095

Autodesk Inc (2020) FBX SDK. http://www. autodesk. com/products/fbx, accessed: 2021-09-20

Baldschuhn R, Binot F, Fleig S, Kockel F (2001) Geotektonischer Atlas von Nordwest-Deutschland und dem-deutschen Nordsee-Sektor. Schweizerbart Science Publishing, Stuttgart, iSBN:978-3-510-95881-8

Bauer S, Beyer C, Dethlefsen F (2013) Impacts of the use of the geological subsurface for energy storage: an investigation concept. Environ Earth Sci 70:3935-3943, DOI:10.1007/s12665-013-2883-0

Bauer S, Dahmke A, Kolditz O (2017) Subsurface energy storage: geological storage of renewable energy - capacities, induced effects and implications. Environ Earth Sci 76:art. 695, DOI:10.1007/s12665-017-7007-9

Bayer P, Attard G, Blum P, Menberg K (2019) The geothermal potential of cities. Renew Sustain Energ Rev 106:17-30, DOI:10.1016/j.rser.2019.02.019

Bhatia S, Cozzi P, Knyazev A, Parisi T (2017) gITF 2.0 Specification. Tech. rep., Khronos Group, URL https://www.khronos.org/gltf/

Brown T, Schlachtberger D, Kies A, Schramm S, Greiner M (2018) Synergies of sector coupling and transmission reinforcement in a cost-optimised, highly renewable European energy system. Energy 160:720-739, DOI:10.1016/j.energy.2018.06.222

Buck V, Stäbler F, González E, Greinert J (2021) Digital Earth Viewer: a 4D Visualisation Platform for Geoscience Datasets. In: Workshop on Visualisation in Environmental Sciences (EnvirVis), The Eurographics Association, DOI:10.2312/envirvis.20211081

Buonocore J, Luckow P, Norris G, et al (2016) Health and climate benefits of different energy-efficiency and renewable energy choices. Nat Clim Change 6:100-105, DOI:10.1038/nclimate2771

Chen M, Lin H, Kolditz O, Chen C (2015) Developing dynamic virtual geographic environments (VGEs) for geographic research. Env Earth Sci 74:6975-6980,

DeJaeger I, Reynders G, Ma Y, Saelens D (2018) Impact of building geometry description within district energy simulations. Energy 158:1060-1069, DOI:10.1016/j.energy.2018.06.098

Elmqvist N, Tsigas P (2008) A Taxonomy of 3D Occlusion Management for Visualization. IEEE Trans Visual Comput Grap 14(5):1095-1109,

Fatima Z, Pollmer U, Santala SS, Kontu K, Ticklen M (2021) Citizens and positive energy districts: Are Espoo and Leipzig ready for PEDs? Buildings 11(3):art. 102, DOI:10.3390/buildings 11030102

Fricke N (2018) Information obligations of district heating supply companies according to §8 of the Energy Transition and Climate Protection Act (EWKG) of Schleswig-Holstein [Informationspflichten för fernwärmeversorgungsunternehmen nach $\S 8$ ewkg schleswig-holstein]. Euroheat and Power/Fernwarme International 47(9):14-18

Gasanzade F, Pfeiffer WT, Witte E, Tuschy I, Bauer S (2021) Subsurface renewable energy storage capacity for hydrogen, methane and compressed air - A performance assessment study from the North German Basin. Renew Sustain Energ Rev 149:art. 111,422, DOI:10.1016/j.rser.2021.111422

González E, Purkiani K, Buck V, Stäbler F, Greinert J (2021) Spatiotemporal Visualisation of a Deep Sea Sediment Plume Dispersion Experiment. In: Workshop on Visualisation in Environmental Sciences (EnvirVis), The Eurographics Association, DOI:10.2312/envirvis.20211082

Günther O (2013) Environmental information systems. Springer Science \& Business Media

Haklay M (1999) From Environmental Information Systems to Environmental Informatics - Evolution and Meaning. Tech. Rep. Paper 7, The Bartlett Centre for Advanced Spatial Analysis, URL https://www.ucl.ac.uk/bartlett/casa/publications/1999/may/casa-working-paper-7

Hassanzadegan A, Cacace M, Sippel J, Scheck-Wenderoth M (2016) The application of inverse modeling in characterizing hydraulic conductivity beneath the city of Berlin, Germany. Environ Earth Sci 75(20):art. 1342, DOI:10.1007/s12665-016-6107-2

Helbig C, Bauer HS, Rink K, Wulfmeyer V, Frank M, Kolditz O (2014) Concept and workflow for 3D visualization of atmospheric data in a virtual reality environment for analytical approaches. Environ Earth Sci 72(10):3767-3780

Helbig C, Dransch D, Böttinger M, Devey C, Haas A, Hlawitschka M, Kuenzer C, Rink K, Schäfer-Neth C, Scheuermann G, et al (2017) Challenges and strategies for the visual exploration of complex environmental data. International Journal of Digital Earth 10(10):1070-1076

Hese F (2012) 3D Modellierungen und Visualisierung von Untergrundstrukturen für die Nutzung des unterirdischen Raumes in Schleswig-Holstein. PhD thesis, Christian-Albrechts Universität Kiel

Jähne-Klingberg F, Wolf M, Steuer S, Bense F, Kaufmann D, Weitkamp A (2014) Speicherpotenziale im zentralen deutschen Nordsee-Sektor. Tech. rep., Bundesanstalt für Geowissenschaften und Rohstoffe, Hannover, Germany

Kabuth A, Dahmke A, Beyer C, et al (2017) Energy storage in the geological subsurface: dimensioning, risk analysis and spatial planning: the ANGUS+ project. Environ Earth Sci 76, DOI:10.1007/s12665-016-6319-5

Kastner O, Norden B, Klapperer S, Park S, Urpi L, Cacace M, Blöcher G (2017) Thermal solar energy storage in Jurassic aquifers in Northeastern Germany: A simulation study. Renew Energ 104:290-306, DOI:10.1016/j.renene.2016.12.003

Kolditz O, Bauer S (2004) A process-oriented approach to computing multi-field problems in porous media. Journal of Hydroinformatics 6:225-244, DOI:10.2166/hydro.2004.0017 
Kolditz O, Bauer S, Bilke L, et al (2012) OpenGeoSys: An open source initiative for numerical simulation of thermo-hydro-mechanical/chemical (THM/C) processes in porous media. Environ Earth Sci 67(2):589-599, DOI:10.1007/s12665-012-1546-x

Krawczyk C, Stiller M, Bauer K, Norden B, Henninges J, Ivanova A, Huenges E (2019) 3-D seismic exploration across the deep geothermal research platform Groß Schönebeck north of Berlin/Germany. Geoth Energ 7(1):art. 1, DOI:10.1186/s40517-019-0131-x

Landesamt für Vermessung und Geoinformation Schleswig-Holstein (2019a) 3D Gebäudemodell LoD1. https://www.schleswig-holstein.de/DE/Landesregierung/LVERMGEOSH/Service/serviceGeobasisdaten/ geodatenService_Geobasisdaten_LoD.html

Landesamt für Vermessung und Geoinformation Schleswig-Holstein (2019b) Digitales Geländemodell 25. https://www.schleswig-holstein.de/DE/Landesregierung/LVERMGEOSH/Service/serviceGeobasisdaten/ geodatenService_Geobasisdaten_DGM.html

Li D, Beyer C, Bauer S (2018) A unified phase equilibrium model for hydrogen solubility and solution density. Int J Hydrogen Energ 43:512-529, DOI:10.1016/j.ijhydene.2017.07.228

Lin H, Chen M, Lu G, et al (2013) Virtual Geographic Environments (VGEs): A New Generation of Geographic Analysis Tool. Earth Sci Rev 126:74-84, DOI:10.1016/j.earscirev.2013.08.001

Masson-Delmotte V, Zhai P, Pörtner HO, et al (2018) IPCC, 2018: Summary for Policymakers. In: Global warming of $1.5^{\circ} \mathrm{C}$. An IPCC Special Report on the impacts of global warming of $1.5^{\circ} \mathrm{C}$ above pre-industrial levels and related global greenhouse gas emission pathways, in the context of strengthening the global response to the threat of climate change, sustainable development, and efforts to eradicate poverty, World Meteorological Organization, Geneva, Switzerland

Müller K (2021) Heat pipelines and climate camps: Coal mining's in/visible infrastructure. Extractive Industries and Society 8(3):art. 100,944, DOI:10.1016/j.exis.2021.100944

Möller B, Wiechers E, Persson U, et al (2019) Heat Roadmap Europe: Towards EU-Wide, local heat supply strategies. Energy 177:554-564, DOI:10.1016/j.energy.2019.04.098

Mouli-Castillo J, Wilkinson M, Mignar D, et al (2019) Inter-seasonal compressed-air energy storage using saline aquifers. Nat Energy 4:131-139, DOI:10.1038/s41560-018-0311-0

Nielsen S (2014) A geographic method for high resolution spatial heat planning. Energy 67:351-362, DOI:10.1016/j.energy.2013.12.011

Nolde M, Schwanebeck M, Dethlefsen F, Biniyaz E, Duttmann R (2016a) Development of a 3D online spatial planning tool aiming to identify subterrestrial search areas potentially suitable for energy storage - Examples from Schleswig-Holstein, Germany [Entwicklung eines 3D-online-planungswerkzeugs zur identifikation untertägiger potenzial-suchräume für die energiespeicherung an beispielen aus Schleswig-Holstein]. gisScience Die Zeitschrift fur Geoinformatik 3(2016):98-105

Nolde M, Schwanebeck M, Dethlefsen F, Duttmann R, Dahmke A (2016b) Utilization of a 3D webGIS to support spatial planning regarding underground energy storage in the context of the German energy system transition at the example of the federal state of Schleswig-Holstein. Environ Earth Sci 75(18):art. 1284, DOI:10.1007/s12665-016-6089-0

Nouvel R, Zirak M, Coors V, Eicker U (2017) The influence of data quality on urban heating demand modeling using 3D city models. Comput Environ Urban Syst 64:68-80, DOI:10.1016/j.compenvurbsys.2016.12.005

Pfeiffer WT, Witte F, Tuschy I, Bauer S (2021) Coupled power plant and geostorage simulations of porous media compressed air energy storage (PM-CAES). Energ Convers Manag 249:art. 114,849, DOI:10.1016/j.enconman.2021.114849

Porter ME, Hill MC, Harris T, Brookfield A, Li X (2021) The DiscoverFramework freeware toolkit for multivariate spatio-temporal environmental data visualization and evaluation. Environ Model Software p art. 105104

QGIS Development Team (2009) QGIS Geographic Information System. http://qgis.osgeo.org

Rink K, Kalbacher T, Kolditz O (2012) Visual data exploration for hydrological analysis. Environ Earth Sci 65(5):1395-1403, DOI:10.1007/s12665-011-1230-6

Rink K, Fischer T, Selle B, Kolditz O (2013) A Data Exploration Framework for Validation and Setup of Hydrological Models. Env Earth Sci 69(2):469-477, DOI:10.1007/s12665-012-2030-3

Rink K, Bilke L, Kolditz O (2014) Visualisation Strategies for Environmental Modelling Data. Environ Earth Sci 72(10):3857-3868, DOI:10.1007/s12665-013-2970-2

Rink K, Nixdorf E, Zhou C, Hillmann M, Bilke L (2020) A Virtual Geographic Environment for Multi-Compartment Water and Solute Dynamics in Large Catchments. J Hydrol 582:art. 124,507, DOI:10.1016/j.jhydrol.2019.124507

Rink K, Sen ÖO, Hannemann M, Ködel U, Nixdorf E, Weber U, Werban U, Schrön M, Kalbacher T, Kolditz O (2021) A Virtual Geographic Environment for the Exploration of Hydro-Meteorological Extremes. In: Workshop on Visualisation in Environmental Sciences (EnvirVis), The Eurographics Association, pp 51-59, DOI:10.2312/envirvis.20211084

Scheck-Wenderoth M, Frick M, Cacace M, Sippel J (2017) Overcoming Spatial Scales in Geothermal Modelling for Urban Areas. Energy Procedia 125:98-105, DOI:10.1016/j.egypro.2017.08.080

Schiebahn S, Grube T, Robinius M, Tietze V, Kumar B, Stolten D (2015) Power to gas: Technological overview, systems analysis and economic assessment for a case study in Germany. Int J Hydrogen Energ 40:4285-4294, DOI:10.1016/j.ijhydene.2015.01.123

Schlumberger Ltd (2018) Petrel E\&P Software platform v2018.1. https://www.software.slb.com/products/petrel

Schroeder W, Martin K, Lorensen B (2006) Visualization Toolkit: An Object-Oriented Approach to 3D Graphics (4th Edition). Kitware, Inc.

Schwanebeck M, Krüger M, Duttmann R (2021) Improving GIS-Based Heat Demand Modelling and Mapping for Residential Buildings with Census Data Sets at Regional and Sub-Regional Scales . Energies 14:art. 1029, DOI:10.3390/en14041029

Spillias S, Kareiva P, Ruckelshaus M, McDonald-Madden E (2020) Renewable energy targets may undermine their sustainability. Nat Clim Change 10:974-976, DOI:10.1038/s41558-020-00939-x 
Tissen C, Menberg K, Bayer P, Blum P (2019) Meeting the demand: geothermal heat supply rates for an urban quarter in Germany. Geoth Energ 7(1), DOI:10.1186/s40517-019-0125-8

Unity Technologies (2020) Unity (Version 2020.1). https://unity3d.com/

Vessey I (2006) The Theory of Cognitive Fit - Once Aspect of a General Theory of Problem Solving. In: Zhang P, Galletta DF (eds) Human-computer Interaction and Management Information Systems: Foundataions, Routledge

Wang B, Bauer S (2016) Converting heterogeneous complex geological models to consistent finite element models: methods, development, and application to deep geothermal reservoir operation. Environ Earth Sci 75:art. 1349, DOI:10.1007/s12665-016-6138-8

Wang D, Guo D, Zhang H (2017) Spatial temporal data visualization in emergency management: a view from data-driven decision. In: Proceedings of the 3rd ACM SIGSPATIAL Workshop on Emergency Management using, pp 1-7

Wate P, Coors V (2015) 3D Data Models for Urban Energy Simulation. Energy Procedia 78:3372-3377, DOI:10.1016/j.egypro.2015.11.753

Weitemeyer S, Kleinhans D, Vogt T, Agert C (2015) Integration of Renewable Energy Sources in future power systems: The role of storage. Renew Energ 75:14-20, DOI:10.1016/j.renene.2014.09.028

Wolf M, Steuer S, Jähne F, Kaufmann D, Weitkamp A (2014) 3D-Lithofaziesmodell des Buntsandstein in der zentralen deutschen Nordsee. Tech. rep., Bundesanstalt für Geowissenschaften und Rohstoffe, Hannover, Germany

Figures

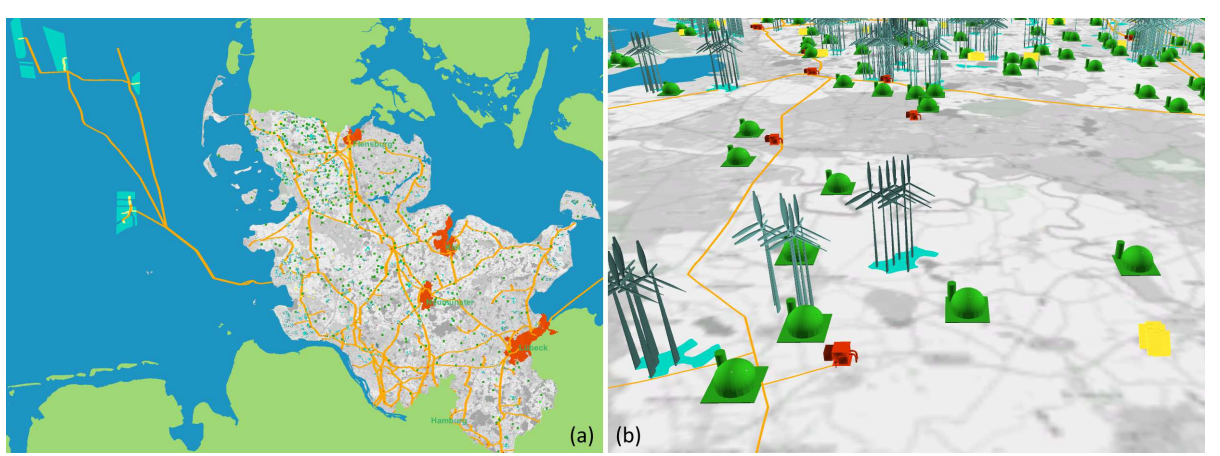

Figure 1 (a) Overview of the state of Schleswig-Holstein displaying representations of the locations of solar parks (yellow), biogas plants (green), wind parks (blue) and transformer stations (red), and power lines (orange) on a high-resolution monochrome map. (b) Detailed isometric view of the region near Hennstett and the river Eider, displaying 3D models for biogas plants (green), wind turbines within wind parks (blue), transformer stations (red) and solar parks (yellow).



Figure 2 (a) Storage formation distribution map below the region of interest. The state of Schleswig-Holstein is shown semi-transparent on top of the layers.(b) CAES simulation result with adiabatic power plant and 9 vertical wells are on the top of anticline structure during storage discharging (timestep 2 of 13). Data in both figures has been superelevated by factor 5 . 

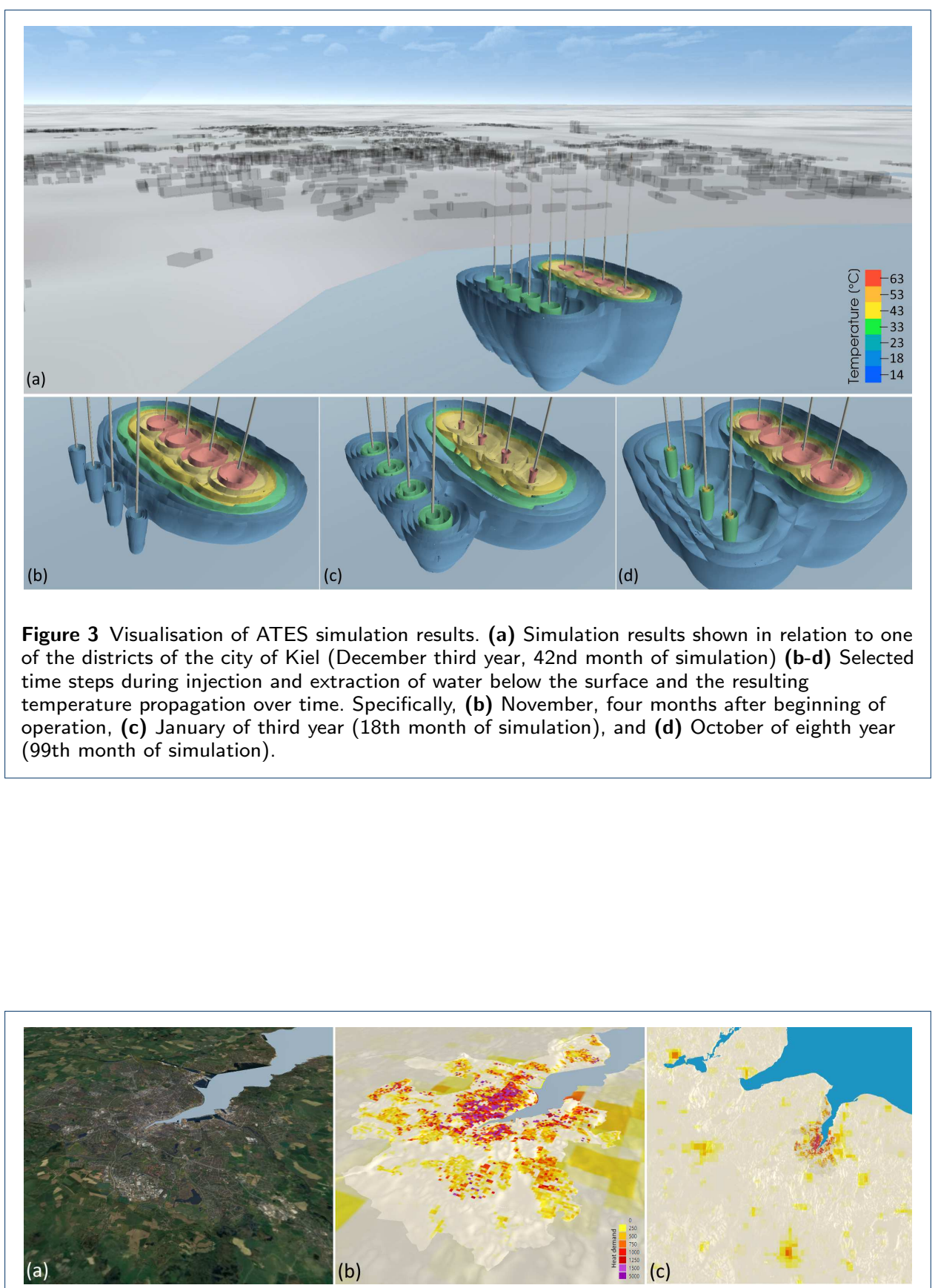

Figure 4 Use of textures for conveying information. (a) For immersion, aerial imagery can be shown mapped onto the surface. Here, the city of Kiel is depicted with a texture at a much higher resolution than the surrounding region. (b) Additional information, such as heat demand density of building stock (in $M H h / h a$ ), can be easy conveyed using textures as well. (c) Again, a higher resolution texture has been applied for the city of Kiel, showing heat demand density at a $1 \mathrm{ha}$ resolution while the general texture for the state has a resolution of $1 \mathrm{~km}^{2}$. 


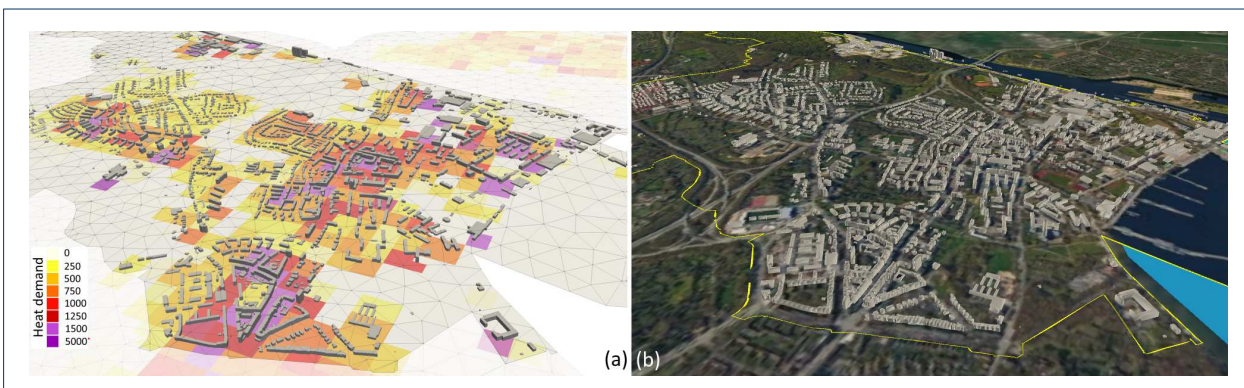

Figure 5 Visualisation of buildings for a district in the city of Kiel. (a) Building models mapped onto a triangulated surface showing heat demand density at a one hectare resolution for the city of Kiel. (b) Buildings models shown on top of aerial imagery. The yellow boundary marks the city district of Kiel for which buildings have been included. 


\section{Supplementary Files}

This is a list of supplementary files associated with this preprint. Click to download.

- videolink.txt 